\title{
Treatment of severe accidental hypothermia with intermittent hemodialysis
}

\author{
Nabil Sultan, MD; ${ }^{*}$ Karl D. Theakston, MD; ${ }^{\dagger}$ Ron Butler, MD $;$ Rita S. Suri, MD*
}

\begin{abstract}
The optimal management of moderate-to-severe hypothermia with hemodynamic instability remains unclear. Although cardiopulmonary bypass offers the most rapid rate of rewarming and has been suggested as the method of choice in the presence of circulatory arrest, there is no evidence to support the use of this highly invasive technique over other rewarming modalities in the absence of circulatory collapse. We report the successful treatment of hemodynamically unstable hypothermia with conventional hemodialysis in a patient with normal renal function, after initial efforts of rewarming using conventional strategies had failed. This case report and review of the literature highlights the advantages and the challenges of using hemodialysis in this setting, and suggests a potential role for hemodialysis in the routine management of moderate-to-severe hypothermia in the absence of circulatory arrest.
\end{abstract}

Keywords: hypothermia, dialysis, rewarming, after-drop, hypotension

\section{RÉSUMÉ}

La prise en charge optimale de I'hypothermie modérée à grave en cas d'instabilité hémodynamique demeure incertaine. Bien que la circulation extracorporelle offre le taux le plus rapide de réchauffement et qu'elle ait été considérée comme la méthode privilégiée en cas d'arrêt circulatoire, aucune preuve ne soutient l'utilisation de cette technique extrêmement invasive plutôt que d'autres méthodes de réchauffement en l'absence de collapsus circulatoire. Nous présentons un cas de prise en charge efficace d'une hypothermie avec instabilité hémodynamique à l'aide d'une hémodialyse classique chez un patient dont la fonction rénale est normale, après avoir utilisé sans succès les techniques habituelles de réchauffement. Ce rapport de cas et la revue de la littérature mettent en évidence les avantages et les défis liés à l'utilisation de l'hémodialyse dans ce contexte et suggèrent que cette méthode pourrait jouer un rôle dans la prise en charge habituelle de l'hypothermie modérée à grave en l'absence d'arrêt circulatoire.

\section{Introduction}

Accidental hypothermia is an unintentional decline in core body temperature to below $35^{\circ} \mathrm{C}$, and is divided into categories of mild $\left(32-35^{\circ} \mathrm{C}\right)$, moderate $\left(28-32^{\circ} \mathrm{C}\right)$ and severe $\left(<28^{\circ} \mathrm{C}\right) .^{1}$ Approximately 600 people die of hypothermia each year in the United States. ${ }^{2}$ Mortality rates because of severe hypothermia vary between $12 \%$ and $80 \%$ in published series, depending on age, comorbidities, intoxication, cause of hypothermia and delays in treatment. ${ }^{3}$

There is still variability in the management of moderateto-severe hypothermia. ${ }^{4}$ Several case series have suggested that the rate of rewarming is an important prognostic factor in severe hypothermia, ${ }^{3,5,6}$ with an in-hospital rewarming

From the *Division of Nephrology, University of Western Ontario, London, Ont., the tDivision of Emergency Medicine, University of Western Ontario, London, Ont., and the $\ddagger$ Division of Critical Care, University of Western Ontario, London, Ont.

Submitted Jan. 14, 2008; Revised Aug. 10, 2008; Accepted Sep. 2, 2008

This article has been peer reviewed.

CJEM 2009;11(2):174-7 
time of longer than 12 hours being associated with higher mortality. ${ }^{7}$ Cardiopulmonary bypass (CPB) provides the most rapid rewarming rate and, if available, is the method of choice in patients with circulatory collapse. However, there is little data that demonstrates its superiority over other modalities in patients without circulatory collapse..$^{8-11}$ Moreover, CPB is restricted to specialized centres, is highly invasive and carries with it a high risk of complications. ${ }^{12}$ Intermittent hemodialysis is an attractive alternative modality for active core rewarming given its wide availability, rapid rewarming rate and its ability to manage associated metabolic derangements. Despite its potential advantages, there have been no trials examining its efficacy. We found only 2 reports on the use of intermittent hemodialysis in hypothermic patients without renal failure. ${ }^{13,14}$ We describe a case of severe hypothermia in a patient without renal failure who was treated with intermittent hemodialysis after initial failed attempts with active external and core rewarming. This case highlights the advantages and challenges of using hemodialysis in treating hypothermia.

\section{Case report}

A 65-year-old homeless man was found lying prone wearing light clothing in a downtown park at 7:30 am on Mar. 30, 2007. The overnight temperature had ranged between $2^{\circ} \mathrm{C}$ and $-1{ }^{\circ} \mathrm{C}$. During the previous evening, the patient had been treated for a laceration and intoxication in the emergency department (ED).

Paramedics found the patient responsive but confused. His Glasgow Coma Scale score was 12, his pulse was 70 beats/min, his blood pressure (BP) was 116/77 mm Hg and his respiratory rate was 16 breaths/min. He was transported to hospital where his first recorded rectal temperature at 8:40 am was $28.9^{\circ} \mathrm{C}$; minutes later, his lowest recorded temperature was $26^{\circ} \mathrm{C}$.

Initial adjusted laboratory investigations revealed the following levels: $\mathrm{pH} 7.27$, bicarbonate $18 \mathrm{mmol} / \mathrm{L}$, sodium $145 \mathrm{mmol} / \mathrm{L}$, potassium $2.4 \mathrm{mmol} / \mathrm{L}$, creatinine $60 \mu \mathrm{mol} / \mathrm{L}$, urea $7.4 \mathrm{mmol} / \mathrm{L}$, hemoglobin $154 \mathrm{~g} / \mathrm{L}$, platelet count $216 \times 10^{9} / \mathrm{L}$, white cell count $13.5 \times 10^{9} / \mathrm{L}$, creatine kinase $530 \mathrm{U} / \mathrm{L}$ and myoglobin $21.9 \mathrm{nmol} / \mathrm{L}$ (normal $<4.8 \mathrm{nmol} / \mathrm{L}$ ). His ethanol level was $60 \mathrm{mmol} / \mathrm{L}$, and the remainder of his toxicology screen was negative. Serial electrocardiograms revealed sinus bradycardia with Osborn waves, QRS widening and nonspecific ST segment changes. A computed tomography scan of the head showed chronic atrophy but no acute changes.

The patient was intubated and ventilated. Active external and core rewarming strategies were initiated, including warming blankets, continuous bladder irrigation, intravenous (IV) fluids warmed to $39-41{ }^{\circ} \mathrm{C}$ and warmed humidified oxygen at a temperature of $39^{\circ} \mathrm{C}$. The patient developed hypotension 70 minutes after arrival at the $\mathrm{ED}$, with a BP of 44/25 mm Hg, measured by automated cuff, and a mean arterial pressure (MAP) of $31 \mathrm{~mm} \mathrm{Hg}$. At 1.5 hours after his admission to the ED, his BP was $83 / 59 \mathrm{~mm} \mathrm{Hg}$ by arterial line, with a MAP of $66.3 \mathrm{~mm} \mathrm{Hg}$. He received $7 \mathrm{~L}$ of warmed crystalloid fluid and multiple doses of phenylephrine, epinephrine and norepinephrine infusions. He had 2 episodes of core temperature afterdrop: his temperature dropped from $28.9^{\circ} \mathrm{C}$ to $27.3^{\circ} \mathrm{C}$ at 1.5 hours after presentation and from $31.4^{\circ} \mathrm{C}$ to $30.6^{\circ} \mathrm{C}$ at just under 6 hours after presentation (Fig. 1). Consequently, 6 hours after presentation his core temperature had only risen by $1.7^{\circ} \mathrm{C}$ (Fig. 1). He continued to be hypotensive, requiring a norepinephrine infusion of 2-13 $\mu \mathrm{g} / \mathrm{min}$, and 7 hours after arrival, he suffered a nadir $\mathrm{BP}$ of $65 / 40 \mathrm{~mm} \mathrm{Hg}$ with a MAP of $40 \mathrm{~mm} \mathrm{Hg}$. His hypotension was exacerbated by episodes of intermittent ventricular tachycardia. Cardiopulmonary bypass was unavailable. More invasive active rewarming such as warm peritoneal and pleural lavage were considered, but given its immediate availability, the decision was made to initiate hemodialysis.

A temporary, double-lumen hemodialysis catheter was inserted into the right internal jugular vein. The patient developed a brief episode of ventricular tachycardia following guidewire insertion. Intermittent hemodialysis was initiated with the following dialysate parameters: temperature $36^{\circ} \mathrm{C}$, potassium $4.0 \mathrm{mmol} / \mathrm{L}$, bicarbonate $40 \mathrm{mmol} / \mathrm{L}$, flow $500 \mathrm{~mL} / \mathrm{min}$ and blood flow $200 \mathrm{~mL} / \mathrm{min}$. The patient's predialysis temperature was $30.6^{\circ} \mathrm{C}$ and after 1 hour

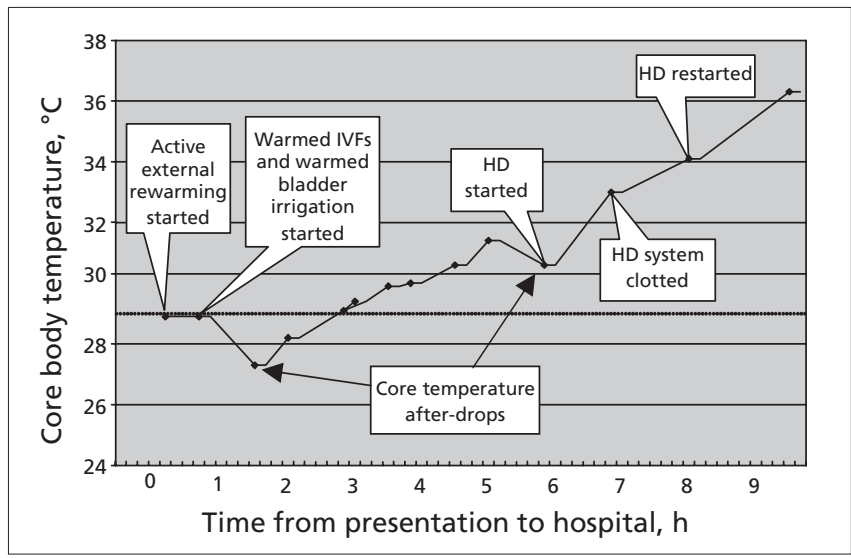

Fig. 1. Graph illustrating our patient's temperature in response to various rewarming strategies. HD = hemodialysis, IVF = intravenous fluid. 
it rose to $33^{\circ} \mathrm{C}$. Thirty minutes after dialysis began, the patient's BP dropped to 73/44 and he experienced a leftsided clonic seizure that was treated with IV lorazepam; the cause of the patient's seizure was not clear. The patient's pre- and postseizure blood glucose levels were $7.2 \mathrm{mmol} / \mathrm{L}$ and $6.6 \mathrm{mmol} / \mathrm{L}$, respectively, and his serum sodium level directly after the seizure was $146 \mathrm{mmol} / \mathrm{L}$. His filter and tubing clotted, and hemodialysis was temporarily stopped.

Because of the temporal relationship between the elevated rate of rewarming and the development of hypotension and seizure, hemodialysis was reinitiated at a dialysate temperature of $35^{\circ} \mathrm{C}$ to slow the rewarming rate, and raised back to $36^{\circ} \mathrm{C} 1$ hour later, though it remained unclear whether the rewarming rate had any role in the patient's adverse events. The potassium bath was increased to $5.0 \mathrm{mEq} / \mathrm{L}$. He received norepinephrine at $13 \mu \mathrm{g} / \mathrm{min}$ throughout hemodialysis. Upon reinitiation of hemodialysis, his temperature rose from $34.1^{\circ} \mathrm{C}$ to $36.3^{\circ} \mathrm{C}$ in 2 hours. Hemodialysis was then stopped, and all inotropes were discontinued. The next morning, the patient was extubated, ate breakfast and was discharged 24 hours later in stable condition.

\section{Discussion}

A case series suggested that CPB is likely the best rewarming method for hypothermia in the presence of circulatory arrest. ${ }^{15}$ Our case suggests that intermittent hemodialysis can be a safe and effective alternative active core rewarming strategy for severe hypothermia in the presence of hemodynamic instability without circulatory arrest.

Like CPB, hemodialysis is an extracoporeal technique that directly warms the core and is more effective than heated oxygen, warmed IV fluids, bladder irrigation and peritoneal lavage. Our patient's average rate of temperature rise using nondialysis rewarming modalities was $0.5^{\circ} \mathrm{C} / \mathrm{h}$. During the first hour of hemodialysis his temperature rose $3{ }^{\circ} \mathrm{C}$ with an average rate of rise of $2.1^{\circ} \mathrm{C} / \mathrm{h}$ (Fig. 1). This rewarming rate is consistent with previous reports (Table 1). ${ }^{9,13,14,16-18}$ Importantly, there were no further incidents of core temperature after-drop during hemodialysis. Although CPB can achieve more rapid rewarming rates of $7-12^{\circ} \mathrm{C} / \mathrm{h}$, the relative benefits and harms of such rapid rewarming rates have not been definitively established. Moreover, CPB is considerably more invasive than hemodialysis, requiring 2 large bore cannula and surgical cutdown or sternotomy. ${ }^{12}$ Cardiopulmonary bypass requires the expertise of a cardiac surgeon and access to a perfusionist, and a hemodialysis catheter can usually be inserted by emergency physicians, intensivists and internists, avoiding delays in initiating treatment. Because of the increasing availability of hemodialysis in smaller communities, clinicians may find the use of locally available hemodialysis to be advantageous to often long transfers to tertiary care centres for $\mathrm{CPB}$ in the immediate management of hypothermia.

Other potential advantages of hemodialysis over CPB include ability to correct electrolyte and acid-base disturbances that often complicate hypothermia even in the absence of renal failure. A further advantage is that heparin can often be successfully replaced by normal saline infusion or other local anticoagulants in hemodialysis to avoid the use of systemic anticoagulation in situations of trauma or hemorrhage that may complicate accidental hypothermia. There are times, however, that systemic anticoagulation is necessary for effective hemodialysis, and in our

\begin{tabular}{|c|c|c|c|c|c|c|c|}
\hline \multirow{2}{*}{$\begin{array}{l}\text { Renal status; } \\
\text { study }\end{array}$} & \multirow{2}{*}{$\begin{array}{l}\text { Patient } \\
\text { age, yr }\end{array}$} & \multirow{2}{*}{$\begin{array}{c}\text { Lowest } \\
\text { temperature, }{ }^{\circ} \mathrm{C}\end{array}$} & \multirow{2}{*}{$\begin{array}{l}\text { Initial rewarming } \\
\text { strategy }\end{array}$} & \multirow[b]{2}{*}{ Mode of HD } & \multicolumn{2}{|c|}{ Rewarming rate, ${ }^{\circ} \mathrm{C} / \mathrm{h}$} & \multirow[b]{2}{*}{ Outcome } \\
\hline & & & & & Off HD & On HD & \\
\hline \multicolumn{8}{|c|}{ Normal renal function } \\
\hline Hernandez et al..$^{13}$ & 34 & 27.0 & Warmed IVFs & IHD & Not specified & 2.15 & Lived \\
\hline Carr et al. ${ }^{14}$ & 35 & 23.9 & $\begin{array}{l}\text { Warmed blankets, warm } \\
\text { inspired air, warmed IVFs }\end{array}$ & IHD & Not specified & 2.80 & Died \\
\hline Komatsu et al. ${ }^{9}$ & 48 & 26.4 & $\begin{array}{c}\text { Convective air warmer, } \\
\text { warmed IVFs }\end{array}$ & CVVH & $\begin{array}{l}\text { Slow (not } \\
\text { specified) }\end{array}$ & 1.37 & Lived \\
\hline $\begin{array}{l}\text { Spooner and } \\
\text { Hassani }{ }^{17}\end{array}$ & 77 & 26.0 & $\begin{array}{l}\text { Heated blankets, } \\
\text { warmed IVFs }\end{array}$ & $\mathrm{CVVH}$ & 0.8 & 4.00 & Lived \\
\hline \multicolumn{8}{|l|}{ Renal failure } \\
\hline Owda and Osama ${ }^{16}$ & 73 & 24.9 & Peritoneal dialysis & IHD & 1.0 & 1.90 & Lived \\
\hline Yokoyama et al..$^{18}$ & 71 & 30.0 & $\begin{array}{l}\text { Heated blankets, } \\
\text { warmed IVFs }\end{array}$ & IHD & Not specified & Not specified & Lived \\
\hline
\end{tabular}


case there was evidence of clotting in the hemodialysis filter despite the use of systemic heparin.

Our case highlights the challenges of using hemodialysis to treat hypothermia. Our patient developed nonsustained ventricular tachycardia with guidewire insertion, likely because of the greater cardiac irritability associated with hypothermia. A femoral approach may have avoided this. Hemodialysis may also result in hemodynamic instability that temporarily worsens, as seen in this case. Whether this was because of the hemodialysis procedure itself or vasodilation caused by the rapidity of rewarming during the first hour is unclear. However, the hemodialysis could be continued with an increase in vasopressor support.

A PubMed search revealed minimal reported use of hemodialysis to treat accidental hypothermia (Table 1). We found 6 reported cases of patients who were treated with hemodialysis for hypothermia, ${ }^{9,13,14,16-18}$ of whom 2 had renal failure. ${ }^{16,18}$ Of the 4 with normal renal function, 2 were treated with intermittent hemodialysis ${ }^{13,14}$ and 2 with continuous hemodialysis. ${ }^{917}$ In contrast, peritoneal dialysis has been more widely used, based on more than 40 published reports. ${ }^{19}$ Hemodialysis may be a more effective rewarming method when compared with peritoneal dialysis, as hemodialysis has been successfully used in peritoneal dialysis failures. ${ }^{13,16}$ Whether continuous hemodialysis is superior to intermittent hemodialysis requires further study.

\section{Conclusion}

Intermittent hemodialysis appears to achieve a relatively rapid and consistent rewarming rate without a core temperature after-drop, and is less invasive and more readily available than CPB. Future studies should compare directly the relative benefits and risks of intermittent hemodialysis with $\mathrm{CPB}$. In the meantime, intermittent hemodialysis should be considered as an alternative to CPB for the treatment of severe hypothermia without circulatory arrest, even in the absence of renal failure.

Acknowledgements: We would like to thank Drs. Jon Trojanowski and Bader Al-Homayeed for the care they provided to this patient. Dr. Suri is supported by a Canadian Institutes of Health Research Randomized Controlled Trials Mentorship Award.

Competing interests: None declared.

\section{References}

1. Jolly BT, Ghezzi KT. Accidental hypothermia. Emerg Med Clin North Am 1992;10:311-27.

2. Centers for Disease Control and Prevention. Hypothermiarelated deaths — United States, 2003. MMWR Morb Mortal
Wkly Rep 2004;53:172-3.

3. Vassal T, Benoit-Gonin B, Carrat F, et al. Severe accidental hypothermia treated in an ICU: prognosis and outcome. Chest 2001;120:1998-2003.

4. Aslam AF, Aslam AK, Vasavada BC, et al. Hypothermia: evaluation, electrocardiographic manifestations, and management. Am J Med 2006;119:297-301.

5. Nicolas F, Nicolas G, Heurtel A, et al. [24 cases of accidental hypothermia] [article in French]. Anesth Analg 1974;31:485-538.

6. Danzl DF, Pozos RS, Auerbach PS, et al. Multicenter hypothermia survey. Ann Emerg Med 1987;16:1042-55.

7. White JD. Hypothermia: the Bellevue experience. Ann Emerg Med 1982;11:417-24.

8. Mair P, Schwarz B, Kornberger E, et al. Case 5-1997. Successful resuscitation of a patient with severe accidental hypothermia and prolonged cardiocirculatory arrest using cardiopulmonary bypass. J Cardiothorac Vasc Anesth 1997;11:901-4.

9. Komatsu S, Shimomatsuya T, Kobuchi T, et al. Severe accidental hypothermia successfully treated by rewarming strategy using continuous venovenous hemodiafiltration system. J Trauma 2007;62:775-6.

10. Steele MT, Nelson MJ, Sessler DI, et al. Forced air speeds rewarming in accidental hypothermia. Ann Emerg Med 1996;27: 479-84.

11. Britt LD, Dascombe WH, Rodriguez A. New horizons in management of hypothermia and frostbite injury. Surg Clin North Am 1991;71:345-70.

12. Shann KG, Likosky DS, Murkin JM, et al. An evidence-based review of the practice of cardiopulmonary bypass in adults: a focus on neurologic injury, glycemic control, hemodilution, and the inflammatory response. J Thorac Cardiovasc Surg 2006;132: 283-90.

13. Hernandez E, Praga M, Alcazar JM, et al. Hemodialysis for treatment of accidental hypothermia. Nephron 1993;63:214-6.

14. Carr ME Jr, Wolfert AI. Rewarming by hemodialysis for hypothermia: failure of heparin to prevent DIC. J Emerg Med 1988;6:277-80.

15. Walpoth BH, Walpoth-Aslan BN, Mattle HP, et al. Outcome of survivors of accidental deep hypothermia and circulatory arrest treated with extracorporeal blood warming. N Engl J Med 1997; 337:1500-5.

16. Owda A, Osama S. Hemodialysis in management of hypothermia. Am J Kidney Dis 2001;38:E8.

17. Spooner K, Hassani A. Extracorporeal rewarming in a severely hypothermic patient using venovenous haemofiltration in the accident and emergency department. J Accid Emerg Med 2000;17: 422-4.

18. Yokoyama M, Noto Y, Kida H. Hypothermia with acute renal failure in a patient suffering from diabetic nephropathy and malnutrition. Diabetes Metab 2000;26:145-7.

19. Mehrotra R. Peritoneal dialysis in adult patients without endstage renal disease. Adv Perit Dial 2000;16:67-72.

Correspondence to: Dr. Rita Suri, Kidney Clinical Research Unit, Rm. ELL-119, Victoria Hospital, London Health Sciences Centre, 800 Commissioners Rd. E, London ON N6A 4G5; rita.suri@lhsc.on.ca 